\title{
A systematic review on the effectiveness of physical and rehabilitation interventions for chronic non-specific low back pain
}

\author{
Marienke van Middelkoop • Sidney M. Rubinstein • \\ Ton Kuijpers • Arianne P. Verhagen · Raymond Ostelo • \\ Bart W. Koes · Maurits W. van Tulder
}

Received: 14 October 2009/Revised: 21 June 2010/ Accepted: 3 July 2010/Published online: 18 July 2010

(C) The Author(s) 2010. This article is published with open access at Springerlink.com

\begin{abstract}
Low back pain (LBP) is a common and disabling disorder in western society. The management of LBP comprises a range of different intervention strategies including surgery, drug therapy, and non-medical interventions. The objective of the present study is to determine the effectiveness of physical and rehabilitation interventions (i.e. exercise therapy, back school, transcutaneous electrical nerve stimulation (TENS), low level laser therapy, education, massage, behavioural treatment, traction,
\end{abstract}

Electronic supplementary material The online version of this article (doi:10.1007/s00586-010-1518-3) contains supplementary material, which is available to authorized users.

M. van Middelkoop $(\bowtie) \cdot$ A. P. Verhagen · B. W. Koes

Department of General Practice, Erasmus MC,

University Medical Center, PO Box 2040,

3000 CA Rotterdam, The Netherlands

e-mail: m.vanmiddelkoop@erasmusmc.nl

S. M. Rubinstein

Department of Epidemiology and Biostatistics

and EMGO-Institute for Health and Care Research,

VU University Medical Center, van der Boechorststraat 7,

1081 BT Amsterdam, The Netherlands

T. Kuijpers

Dutch Institute for Health Care Improvement CBO,

Utrecht, The Netherlands

R. Ostelo

Department of Health Sciences and EMGO-Institute for Health and Care Research, VU University Medical Center,

Amsterdam, The Netherlands

M. W. van Tulder

Department of Health Sciences and EMGO-Institute for Health and Care Research, Faculty of Earth and Life Sciences,

VU University, Amsterdam, The Netherlands multidisciplinary treatment, lumbar supports, and heat/cold therapy) for chronic LBP. The primary search was conducted in MEDLINE, EMBASE, CINAHL, CENTRAL, and PEDro up to 22 December 2008. Existing Cochrane reviews for the individual interventions were screened for studies fulfilling the inclusion criteria. The search strategy outlined by the Cochrane Back Review Groups (CBRG) was followed. The following were included for selection criteria: (1) randomized controlled trials, (2) adult ( $\geq 18$ years) population with chronic ( $\geq 12$ weeks) nonspecific LBP, and (3) evaluation of at least one of the main clinically relevant outcome measures (pain, functional status, perceived recovery, or return to work). Two reviewers independently selected studies and extracted data on study characteristics, risk of bias, and outcomes at short, intermediate, and long-term follow-up. The GRADE approach was used to determine the quality of evidence. In total 83 randomized controlled trials met the inclusion criteria: exercise therapy $(n=37)$, back school $(n=5)$, TENS $(n=6)$, low level laser therapy $(n=3)$, behavioural treatment $(n=21)$, patient education $(n=1)$, traction $(n=1)$, and multidisciplinary treatment $(n=6)$. Compared to usual care, exercise therapy improved post-treatment pain intensity and disability, and long-term function. Behavioural treatment was found to be effective in reducing pain intensity at short-term follow-up compared to no treatment/waiting list controls. Finally, multidisciplinary treatment was found to reduce pain intensity and disability at short-term follow-up compared to no treatment/waiting list controls. Overall, the level of evidence was low. Evidence from randomized controlled trials demonstrates that there is low quality evidence for the effectiveness of exercise therapy compared to usual care, there is low evidence for the effectiveness of behavioural therapy compared to no treatment and there is moderate evidence for the 
effectiveness of a multidisciplinary treatment compared to no treatment and other active treatments at reducing pain at short-term in the treatment of chronic low back pain. Based on the heterogeneity of the populations, interventions, and comparison groups, we conclude that there are insufficient data to draw firm conclusion on the clinical effect of back schools, low-level laser therapy, patient education, massage, traction, superficial heat/cold, and lumbar supports for chronic LBP.

Keywords Systematic review - Exercise - Back school . TENS · Education · Multidisciplinary · Behavioural ·

Effectiveness of interventions - Efficacy - Low back pain . Meta-analyses · Treatment effects · Rehabilitation

Conservative

\section{Background}

Low back pain (LBP) is related to disability and work absence and accounts for high economical costs in western societies [1]. The management of LBP comprises a range of different intervention strategies including surgery, drug therapy, and non-medical interventions. During the last years, a large number of randomized controlled trials (RCTs) have been published and these have been summarized in systematic reviews. Most of these systematic reviews focus on the effectiveness of a single intervention and describe the effectiveness on the different types of LBP. The current study presents an upto-date overview on the current literature on physical and rehabilitation medicine in patients with chronic LBP. The physical and rehabilitation medicine interventions include exercise therapy, back schools, transcutaneous electrical nerve stimulation (TENS), superficial heat or cold, lowlevel laser therapy (LLLT), individual patient education, massage, behavioural treatment, lumbar supports, traction, and multidisciplinary rehabilitation. This systematic review will provide an overview on these physical and rehabilitation medicine interventions applied in chronic LBP patients and its effectiveness.

\section{Criteria for considering studies for this review}

A study must fulfil the following inclusion criteria to be included in this review.

Types of studies

Only RCTs were included.
Types of participants

The study population should consist of adults, older than 18 years, with non-specific chronic LBP that persisted for 12 weeks or more.

Randomized controlled trials (RCTs) including subjects with specific LBP caused by pathological entities, such as vertebral spinal stenosis, ankylosing spondylitis, scoliosis, and coccydynia were excluded. The diagnosis for these specific entities had to be confirmed by means of an MRI or another diagnostic tool. Trials on post-partum LBP or pelvic pain due to pregnancy as well as post-operative studies and prevention studies were also excluded.

Types of interventions

Randomized controlled trials (RCTs) studying the following physical and rehabilitation interventions were included in this overview: exercise therapy, back schools, transcutaneous electrical nerve stimulation (TENS), superficial heat or cold, low-level laser therapy (LLLT), individual patient education, massage, behavioural treatment, lumbar supports, traction, and multidisciplinary rehabilitation.

Exercise therapy was defined as "a series of specific movements with the aim of training or developing the body by a routine practice or physical training to promote good physical health" [2].

A back school was defined as consisting of educational and skills acquisition program, including exercises, in which all lessons were given to groups of patients and supervised by a paramedical therapist or medical specialist [3].

All standard modes of transcutaneous electrical nerve stimulation (TENS) were considered in this review. TENS is a non-invasive therapeutic modality. TENS units stimulate peripheral nerves via skin surface electrodes at well-tolerated intensities and are capable of being selfadministered [4].

Superficial heat or cold included all kinds of heat or cold therapies, such as ice, cold towels, cold gel packs, ice packs, and ice massage; hot water bottles, heated stones, soft-heated packs filled with grain, poultices, hot towels, hot baths, saunas, steam, heat wraps, heat pads, electric heat pads, and infrared heat lamps [5]. Spa therapy (balneotherapy) was excluded.

Low-level laser therapy (LLLT) is a light source that generates pure light of a single wavelength with nonthermal effects [6]. For this intervention, all types of LLLT, including all wavelengths, are included.

Patient education was defined as "a systematic experience, in a one-to-one situation, that consists of one or more 
methods, such as the provision of information and advice and behaviour modification techniques, which influence the way the patient experiences his illness and/or his knowledge and health behaviour, aimed at improving or maintaining or learning to cope with a condition" [7].

Massage was defined as soft tissue manipulation using the hands or a mechanical device [8].

Behavioural treatments included operant, cognitive, and respondent treatments or a combination of these treatments. Each of these focus on the modification of one of the three response systems that characterize emotional experiences: behaviour, cognition, and physiological reactivity [9].

Lumbar supports included any type of lumbar support, flexible or rigid, used for the treatment of chronic nonspecific LBP [10].

The intervention traction included any type of traction, such as mechanical traction, manual traction (unspecific or segmental traction), computerized traction, auto traction, underwater traction, bed rest traction, inverted traction, continuous traction, and intermitted traction [11].

Finally, the multidisciplinary treatment included multidisciplinary bio-psychosocial rehabilitation with minimally one physical dimension and one of the other dimensions (psychological or social or occupational) [12].

For all types of interventions, additional treatments were allowed, provided that the intervention of interest was the main contrast between the intervention groups included in the study.

\section{Types of outcome measures}

The following self-reported outcome measures were assessed in this review: pain intensity (e.g. visual analogue scale (VAS), McGill pain questionnaire), back-specific disability (e.g. Roland Morris, Oswestry Disability Index), perceived recovery (e.g. overall improvement), return to work (e.g. return to work status, sick leave days), and side effects. The primary outcomes for this overview were pain and physical functional status. Studies with a follow-up less than one day were excluded.

\section{Search methods for identification of studies}

Existing Cochrane reviews of the 11 interventions were screened for studies fulfilling the inclusion criteria. Additionally, a search was conducted in MEDLINE, EMBASE, CINAHL, CENTRAL, and PEDro up to 22 December 2008. The searches were updated from the last date of the literature search in the Cochrane reviews.

References from the relevant studies were screened, and experts were approached in order to identify any additional primary studies not identified in the previous steps. The language was limited to English, Dutch, and German, because these were the languages that the review authors were able to read and understand. The search strategy outlined by the Cochrane Back Review Group (CBRG) was perused. Two reviewers working independently from each other conducted the electronic searches.

\section{Methods of the review}

Study selection

Three authors (MM and SR/TK) independently screened the abstracts and titles retrieved by the search strategy and applied the inclusion criteria to all these abstracts. Full text of the article was obtained if the abstract seemed to fulfil the inclusion criteria or if eligibility of the study was unclear. All full text articles were compiled and screened on inclusion criteria by the two authors, independently. Any disagreements between the authors were resolved by discussion and consensus. A third author was consulted if disagreements persisted.

Assessment of risk of bias in included studies

Two reviewers (MM, SMR) conducted the risk of bias assessment, independently. Risk of bias of the individual studies was assessed using the criteria list advised by the CBRG, which consists of 11-items. Items were scored as positive if they did fulfil the criteria and negative when there was a clear risk of bias, and marked as inconclusive if there was insufficient information. Differences in assessment were discussed during a consensus meeting. A total score was computed, and high quality was defined as fulfilling six or more (more than $50 \%$ ) of the internal validity criteria (range 0-11).

\section{Data extraction}

The same two review authors who performed the risk of bias assessment conducted the data extraction, independently from one another. Data were extracted onto a standardized web-based form. The following data were extracted from the studies: (1) characteristics of the studies: number of participants, gender, age, setting, and duration of complaints; (2) characteristics of the interventions: the type, frequency, duration, co-interventions, and control intervention; (3) characteristics of the outcomes: outcome measures, instruments, and scores (e.g. mean, median, standard deviation, and confidence interval). 
Data analysis and statistical analysis

Comparison therapies were combined into main clusters of presumed effectiveness (no treatment/waiting list controls, other interventions). Separate analyses were planned for: (1) each type of intervention, (2) each type of control, (3) each main outcome measure, and (4) time of follow-up (post-treatment; short-term (closest to 3 months), intermediate (closest to 6 months), and long-term (closest to 12 months) follow-up).

If trials reported outcomes only as graphs, the mean scores and standard deviations were estimated from these graphs (Supplementary material).

For continuous data results are presented as weighted mean differences (WMD). All scales were converted to 100-point scales. For dichotomous data, a relative risk (RR) was calculated, and the event was defined as the number of subjects recovered. A test for heterogeneity was calculated using the Q-test (Chi-square) and $I^{2}$. Confidence intervals $(95 \% \mathrm{CI})$ were calculated for each effect. A random effects model was used and funnel plots were examined for publication bias.

If standard deviations were not reported, we calculated it using reported values of confidence intervals if possible. If the standard deviation of the baseline score was reported, this score was forwarded. Finally, if none of these data were reported, an estimation of the standard deviation was based on study data (population and score) of other studies.

To correct for bias introduced by "double-counting" of subjects of trials that had two control groups in the same meta-analyses, the number of subjects of these trials were divided by two.

\section{Quality of evidence}

Grades of Recommendation, Assessment, Development, and Evaluation (GRADE) were used to evaluate the overall quality of evidence and the strength of the recommendations [13]. Quality of evidence of a specific outcome was based upon four principal measures: (1) limitations (due to for example, study design), (2) consistency of results, (3) indirectness (e.g. generalizability of the findings), (4) precision (e.g. sufficient data), and (5) other considerations, such as reporting bias. The overall quality was considered to be high when RCTs with a low risk of bias provide consistent, sufficient, and precise results for a particular outcome; however, the quality of the evidence was downgraded by one level when one of the factors described above was not met. The following grades of evidence were applied:

High quality:

Further research is very unlikely to change our confidence in the estimate of effect.
Moderate quality: Further research is likely to have an important impact on our confidence in the estimate of effect and may change the estimate.

Low quality: $\quad$ Further research is very likely to have an important impact on our confidence in the estimate of effect and is likely to change the estimate.

Very low quality: We are very uncertain about the estimate.

To improve the readability of this review, a GRADE table was completed only when we completed a meta-analysis.

\section{Results}

Description of studies

Of the 11 existing Cochrane reviews a total of 114 full text articles were screened for eligibility. Of these 114 articles, 58 studies fulfilled the inclusion criteria and were included. Additionally, 1,825 new relevant titles and abstracts were identified and screened for potential inclusion (Fig. 1). Of these, 127 full text articles were evaluated of which a total of 35 studies fulfilled the inclusion criteria.

After removing duplicates, 83 studies were included, comprising the following subjects: exercise therapy [14-50] $(n=37)$, back schools [51-55] $(n=5)$, TENS [56-61] $(n=6)$, low-level laser therapy [62-64] $(n=3)$, massage [65-67] $(n=3)$, behavioural treatment [68-88] $(n=21)$, patient education [89] $(n=1)$, traction [90] $(n=1)$, and multidisciplinary treatment [91-96] $(n=6)$.

Multiple publications were found for Bendix et al. [15, 92, 97], Gudavalli et al. [26, 98, 99], Härkäpää et al. [96, 100-102], Niemistö et al. [35, 103], Smeets et al. [41, 104], and Tavafian et al.[54, 105]. Information from all publications was used for assessment of risk of bias and data extraction, but only the first or most prominent publication was used for citation of these studies.

The study characteristics of all included studies are presented in Table 1.1 to 1.9 in Supplementary material. A total of 8,816 patients were included. Most patients were included in the exercise studies $(n=3,957)$, followed by the behavioural studies ( $n=2,062)$, and multidisciplinary studies $(n=1,229)$. A total of 50 studies $(60 \%)$ reported on the outcome pain intensity, measured with a VAS or numerical rating scale (NRS). In total, 11 studies $(13.3 \%)$ did not report on the outcome pain.

Risk of bias assessment

The results of the risk of bias assessment are shown in Table 1. All studies were described as randomized, 
Fig. 1 Flow diagram of systematic review inclusion and exclusion of articles for nonmedical treatments for chronic low back pain

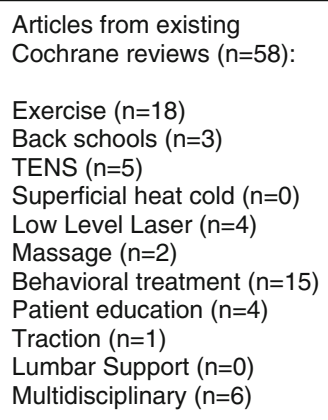

however, the method of randomization was only explicit in $56.6 \%(n=47)$ of the studies. Only 28 studies $(33.7 \%)$ met six or more of the criteria, which was our preset threshold for low risk of bias. Only the criteria regarding the baseline characteristics, timing of outcome measures, and description of dropouts were met by $50 \%$ or more of the included randomized trials. Compliance of the interventions was clearly acceptable in only $37.3 \%$ $(n=31)$.

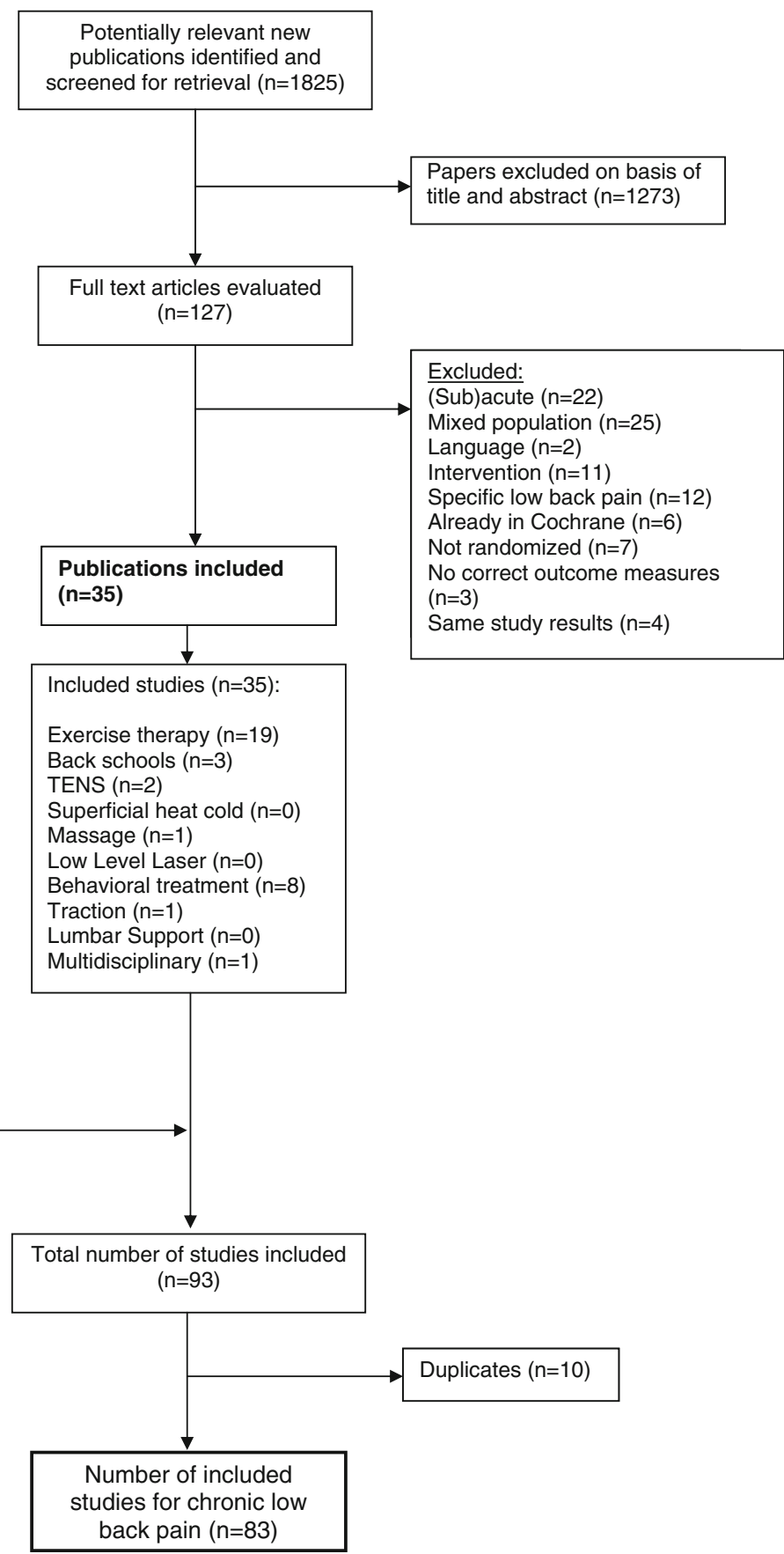

\section{Effects of intervention}

The effectiveness of exercise therapy

Exercise therapy versus waiting list controls/no treatment

Eight studies [14, 23, 24, 36, 40, 41, 43, 48] were identified as comparing some type of exercise therapy to waiting list controls or no treatment. Five studies reported 


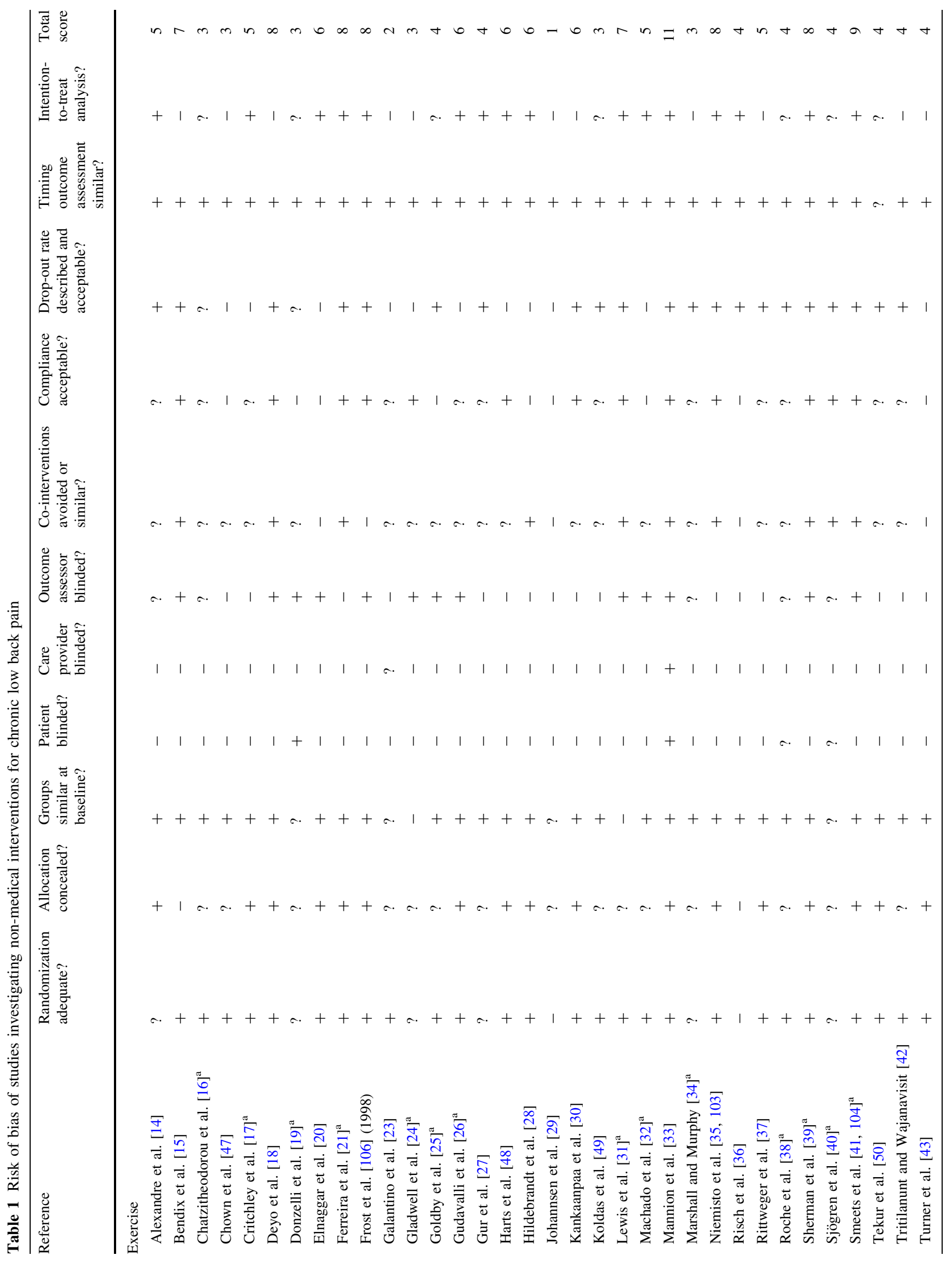




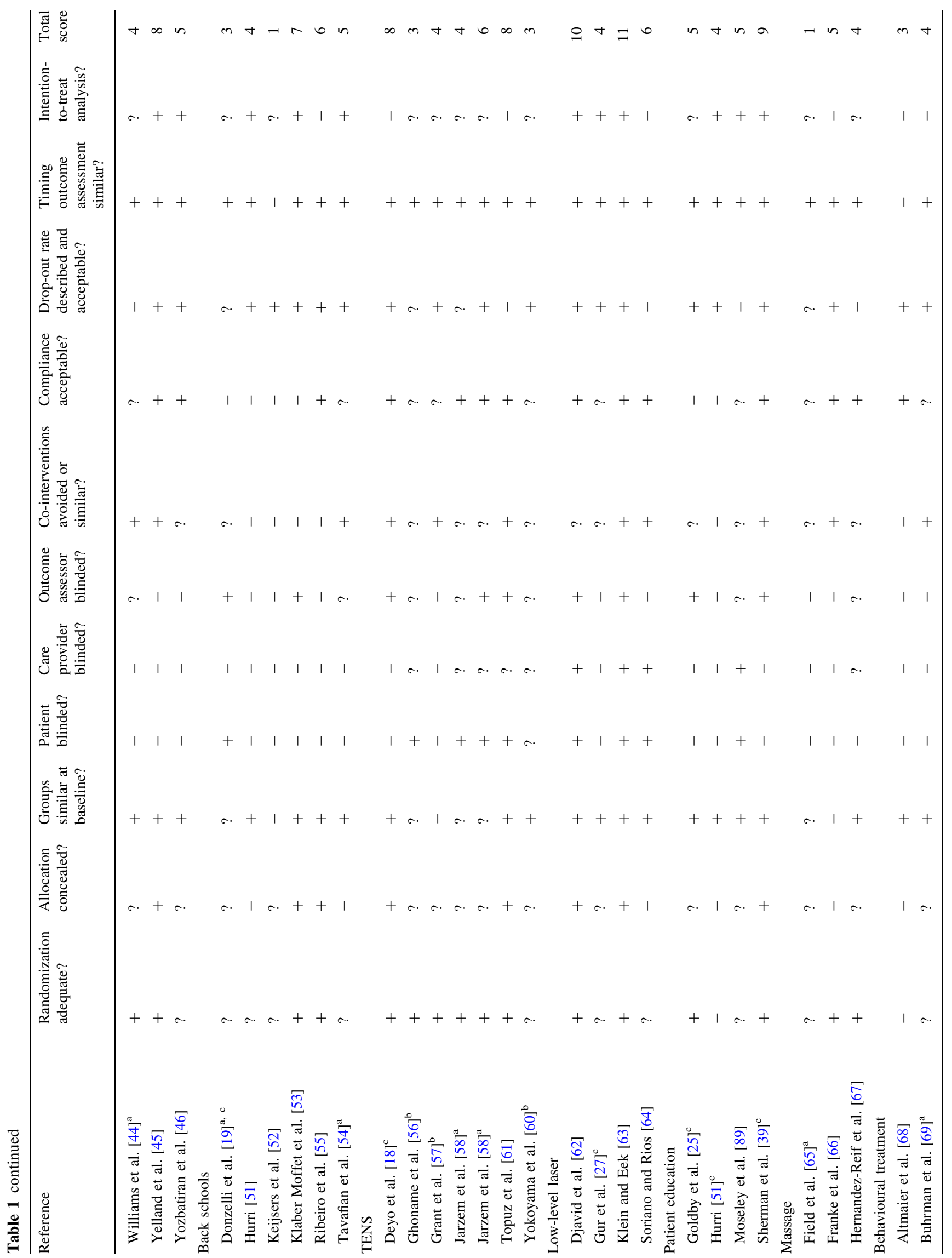







post-treatment data only, because after the treatment period the waiting list controls also received the treatment. Only two studies $[14,41]$ had intermediate or long-term follow-up.

All studies reported data that could be used in the statistical pooling. The pooled mean difference of the five studies reporting post-treatment pain intensity was not statistically significant $(-4.51$ [95\% CI $-9.49 ; 0.47])$. The WMD for post-treatment improvement in disability was -3.63 [95\% CI $-8.89 ; 1.63]$. The pooled mean WMD for pain intensity at intermediate follow-up was -16.46 [95\%CI $-44.48 ; 11.57]$. Only one study (102 people) reported intermediate outcomes for disability and longterm outcomes for pain intensity and disability. There were no differences between the groups receiving exercise therapy and the waiting list control group.[41].

Therefore, there is low quality evidence (serious limitations, imprecision) that there is no statistically significant difference in pain reduction and improvement of disability between exercise therapy and no treatment/waiting list controls.

\section{Exercise therapy versus usual careladvise to stay active}

A total of six studies $[28,35,45,49,50,106]$ investigated the effect of exercise therapy compared to usual care. Four of these studies had an intermediate or long-term followup. Statistical pooling of three studies $[49,50,106]$ showed a significant decrease in pain intensity and disability in favour of the exercise group (WMD -9.23 [95\%CI $-16.02 ;-2.43])$ and -12.35 [95\%CI $-23.00 ;-1.69$ ], respectively. One study [49] reported on pain and disability at short-term follow-up, and found no statistically significant differences between the exercise group and the control group receiving home exercises. Two studies [35, 106] showed a statistically significant pooled WMD for disability at intermediate follow-up of -5.43 [95\%CI -9.54 ; -1.32]. One study [35] found a statistically significant difference at intermediate follow-up for pain relief for the exercise group compared to the usual care group. Three studies $[45,103,106]$ reported on pain and/or disability at long-term follow-up. The pooled WMD for pain was not statistically significant $(-4.94$ [95\%CI $-10.45 ; 0.58])$; the WMD for disability was statistically significant in favour of the exercise group (WMD -3.17 [95\%CI -5.96; $-0.38])$.

One study [28] reported recovery at post-treatment and during intermediate and long-term follow-up. There was a statistically significant difference between the groups at 3 and 6 months follow-up in favour of the exercise group compared with usual care $(p<0.001)$. As much as $80 \%$ of the patients in the exercise group regarded themselves as recovered at 3 months follow-up versus $47 \%$ in the usual care group.
There is low quality evidence (serious limitations, imprecision) for the effectiveness of exercise therapy compared to usual care on pain intensity and disability.

\section{Exercise therapy versus back school/education}

Four studies, three with a high risk of bias, were identified $[19,25,39,44]$. Post-treatment results for disability were reported in two studies, with a significant pooled WMD of $-11.20[95 \% \mathrm{CI}-16.78 ;-5.62]$. One study reported on pain post-treatment and found no statistically significant difference between both the intervention groups [44]. The pooled mean differences for pain and disability at 3 months follow-up were $-7.63[95 \% \mathrm{CI}-17.20 ; 1.93]$ and -2.55 [95\%CI $-10.07 ; 4.97]$, respectively.

Two studies $[19,25]$ reported intermediate outcomes on pain and three studies $[19,25,39]$ reported on disability. The pooled WMDs showed no statistically significant differences between the groups: -5.58 [95\% CI $-16.65 ; 5.48]$ and -4.42 [95\%CI $-9.90 ; 1.05]$, respectively. Only one study $(n=346)$ reported long-term outcomes, and these were not statistically significantly different between the groups [25].

The data provided very low quality evidence (serious limitations, imprecision, and inconsistency) that there was no statistically significant difference in effect on pain and disability at short- and intermediate follow-up for exercise therapy compared to back school/education.

\section{Exercise therapy versus behavioural treatment}

Three studies, one with a low risk of bias, were identified comparing exercise therapy with a behavioural treatment $[17,41,43]$. Two studies reported post-treatment pain and disability and the pooled WMDs were 1.21 [95\% CI -5.42 ; 7.84] and 0.34 [95\% CI $-2.64 ; 3.31$ ], respectively.

All three studies reported intermediate and long-term follow-up on pain intensity and disability. For intermediate follow-up the pooled WMDs for pain and disability were -2.23 [95\% CI - 7.58; 3.12] and 1.97 [95\% CI -3.55; 7.48], respectively. Long-term results showed a pooled WMD for pain intensity of $-0.88[95 \% \mathrm{CI}-6.34 ; 4.58]$ and a pooled WMD for disability of 2.77 [ $95 \% \mathrm{CI}-3.43 ; 8.96]$.

There is low quality evidence (serious limitations, imprecision) that there are no statistically significant differences between exercise therapy and behavioural therapy on pain intensity and disability at short- and long-term follow-up.

\section{Exercise therapy versus TENS/laser therapy/ultrasound/ massage}

Five studies, two with a low risk of bias, were identified comparing exercise therapy with passive therapies, such as 
TENS, low-level laser therapy, ultrasound, thermal therapy, and ultrasound [16, 18, 27, 30, 49]. The pooled WMD for post-treatment pain intensity was -9.33 [95\% CI $-18.80 ; 0.13]$ and for post-treatment disability -2.59 [95\% CI $-8.03 ; 2.85]$. Two studies [18, 49] reported on short-term pain intensity and disability and the pooled mean differences were 1.72 [95\% CI $-6.05 ; 9.50]$ and 1.02 [95\% CI $-0.38 ; 2.42]$, respectively. One study with a low risk of bias [30] reported intermediate and long-term outcomes, and found a statistically significant difference for pain intensity of 16.8 and 21.2 points, respectively, in favour of exercise therapy. Also a statistically significant difference was found for disability.

Low quality evidence (serious limitations, inconsistency, and imprecision) was provided that there is no statistically significant difference in effect between exercise therapy compared to TENS/laser/ultrasound/massage on the outcomes pain and disability at short-term follow-up.

\section{Exercise therapy versus manual therapy/manipulation}

Five studies, two with a low risk of bias, were identified comparing exercise treatment with spinal manipulation or manual therapy $[21,25,26,34,47]$. Post-treatment data were available for three studies. The pooled WMDs for pain intensity and disability were 5.67 [95\%CI 1.99; 9.35] and 2.16 [95\% CI $-0.96 ; 5.28]$, respectively. One study reported a statistically significant difference in global perceived effect post-treatment [21] in favour of spinal manipulation. Two studies reported short-term effects on pain intensity and disability and the pooled WMDs were -1.33 [95\%CI $-10.11 ; 7.79]$ and 0.29 [95\%CI -3.15 ; $3.72]$, respectively $[25,26]$. Intermediate results on pain and disability were reported by three studies [21, 25, 26] and the pooled WMDs were -0.49 [95\% CI $-12.22 ; 11.23$ ] and 2.38 [95\%CI -5.16; 9.93], respectively. All studies reported long-term results on disability and the pooled WMD -0.70 [95\%CI $-3.14 ; 1.74]$. Four studies reported long-term results on pain intensity and the pooled WMD was 2.09 [95\%CI $-2.94 ; 7.13]$. Global perceived effect was reported by one study during intermediate and longterm follow-up. No statistically significant between group differences were found in this study [21].

The data provided low quality evidence (inconsistency, imprecision) that there was no statistically significant difference in effect (pain intensity and disability) for exercise therapy compared to manual therapy/manipulation at shortand long-term follow-up.

\section{Exercise therapy versus psychotherapy}

One study with a high risk of bias was identified [32]. Posttreatment results showed a statistically significant difference in disability scores between both groups in advantage of the exercise group. No post-treatment differences between both groups were found for pain intensity. At 6 months followup, both disability and pain intensity scores were lower in the exercise group compared to the psychotherapy group, but not statistically significant.

\section{Exercise therapy versus other forms of exercise therapy}

As much as 11 studies compared different exercise interventions with each other $[20,21,29,31,33,37-39,42$, $46,48]$. Data of these studies could not be pooled because of the heterogeneity of the types of interventions.

Two studies found statistically significant differences between different exercise interventions. One study [42], with a high risk of bias, reported statistically significant difference in pain relief at 3 months follow-up of an aerobic exercise training program compared with a lumbar flexion exercise program of 3 months. One large trial [21] with a low risk of bias $(n=240)$ compared a general exercise program (strengthening and stretching) with a motor control exercise program (improving function of specific trunk muscles) of 12 weeks. The motor control exercise group had slightly significantly better outcomes (mean adjusted between group difference function 2.9 and global perceived effect 1.7) than the general exercise group at 8 weeks. Similar group outcomes were found at 6 and 12 months follow-up.

A total of eight studies did not find any statistically significant differences between the various exercise interventions [20, 29, 31, 33, 37, 38, 46, 48]. Sherman et al. [39] compared a 12-week yoga (viniyoga) program with a 12-week conventional exercise class program. Back-related function in the yoga group was superior to the exercise group at 12 weeks.

The effectiveness of back school

Back school versus waiting list controls/no treatment/usual care

Three studies compared back school with waiting list controls, no treatment, and a usual care clinic group [52, 54, 55]. Pain post-treatment was reported by 2 studies $[52,55]$ and the pooled WMD was -4.64 [95\%CI $-13.65 ; 4.37]$. Disability post-treatment was only reported by Ribeiro et al. [55] and showed no statistically significant difference between both groups. Two studies $[54,55]$ reported shortterm follow-up data on disability and the pooled WMD was -13.04 [95\% CI $-37.04 ; 10.95]$ in favour of the back school intervention. One study [55] with a low risk of bias reported on pain intensity at short-term follow-up and found no statistically significant difference between both intervention 
groups. One study [54] with a high risk of bias, reported on disability at intermediate and long-term follow-up and no significant differences were found at both time points between the back school group and the clinic group.

Due to serious limitations, inconsistency, and imprecision, low quality evidence was provided that there is no statistically significant short-term difference in treatment effect on pain and disability for a back school treatment compared to waiting list controls/no treatment/usual care.

\section{Back school versus active treatment}

Two studies, one with a low risk of bias, were identified comparing a back school treatment with an active treatment $[19,53]$. The pooled WMDs for pain intensity and disability at short-term follow-up were 4.75 [95\%CI -2.13; 11.63] and 0.12 [95\%CI $-2.37 ; 2.61]$, respectively. At intermediate follow-up, the pooled WMDs for pain intensity and disability were $-2.16[95 \% \mathrm{CI}-13.03 ; 8.71]$ and 0.05 [-3.59; 3.69], respectively.

Low quality evidence (serious limitations, inconsistency, and imprecision) was provided that there is no statistically significant difference in effect for back school treatment compared to active treatments on pain and disability at short-term and intermediate follow-up.

\section{Back school versus education/information}

One study [51] with a high risk of bias was identified comparing back school with given instructional material. At 6 months follow-up, there was a statistically significant difference in pain intensity and disability in favour of the back school group. At long-term follow-up (12 months), there was still a significant difference between both intervention groups on the outcome disability, but not for pain intensity, in favour of the back school group.

The effectiveness of transcutaneous electrical nerve stimulation (TENS)

\section{TENS versus sham treatment}

Five studies, two with a low risk of bias, compared the effectiveness of TENS with sham TENS or sham percutaneous electrical nerve stimulation (PENS). Four studies $[18,56,59,61]$ described post-treatment results on pain and the pooled WMD was -4.47 [95\%CI $-12.84 ; 3.89]$. The pooled WMD of post-treatment disability of two studies [18, 61] was -1.36 [95\%CI $-4.38 ; 1.66]$. Ghoname et al. [56] reported on disability and found no significant difference between the TENS and sham-PENS group. The study of Jarzem et al. [59] with a low risk of bias, compared TENS with sham-TENS and demonstrated a significant carry-over effect with conventional TENS having a greater effect on pain intensity than sham-TENS.

Two studies [18, 58] found no statistically significant difference between the TENS and sham TENS groups at short-term follow-up.

The data provided low quality evidence (serious limitations, heterogeneity) that there is no statistically significant difference on post-treatment pain intensity and disability between TENS and sham-TENS.

\section{TENS versus PENS/acupuncture}

Four studies, all with a high risk of bias, compared the effectiveness of TENS with acupuncture or PENS [56-58, $60]$. Post-treatment results of two studies [56, 60] showed a pooled WMD for pain intensity of 16.64 [95\%CI 5.86; $27.41]$, in favour of the control group. Outcomes on shortterm pain intensity were reported in three studies [57, 58, 60]. The pooled WMD was 6.51 [95\%CI -0.41; 13.44] in favour of the PENS/acupuncture intervention. One study [58], with a high risk of bias, reported no statistically significant difference on short-term disability.

Very low quality evidence (serious limitations, inconsistency, and imprecision) was provided that PENS/acupuncture is more effective than TENS for post-treatment and short-term pain relief.

\section{TENS versus active treatments}

Two studies, of which one with a high risk of bias, compared the effectiveness of TENS with active treatments [18, 56]. Ghoname et al. found no statistically significant difference in pain intensity post-treatment between both intervention groups. Deyo et al. [18] reported no statistically significant difference on pain intensity, disability, and recovery at short-term follow-up between TENS and exercise therapy.

\section{Conventional TENS versus biphasic new wave TENS}

One study [58] with a high risk of bias investigated the effectiveness of conventional TENS compared to biphasic new wave TENS for the outcomes of pain and disability post-treatment and at short-term follow-up. No statistically significant differences were found for both outcome measures at both time points.

The effectiveness of low-level laser therapy (LLLT)

Low-level laser therapy versus sham treatment

One study [64] with a low risk of bias, compared low-level laser therapy treatment with sham laser therapy treatment 
in elderly patients over 60 years. The study provided low quality evidence that LLLT was more effective in pain relief at intermediate follow-up (44.7\%) compared with sham LLLT $(15.2 \%)$.

\section{Low-level laser therapy + exercise versus} sham LLLT + exercise

Results on pain and disability at post-treatment were reported by one study [62] and no difference was found between the intervention groups on both outcome measures.

Two studies [62, 63] reported on pain intensity and disability at short-term (3 months) follow-up. The pooled analysis of these two small trials $(n=61)$ showed a significant difference in pain relief (WMD - 13.57 [95\%CI $-26.67 ;-0.47])$. No difference was found on disability between those who received LLLT plus exercise and those who received sham LLLT + exercise (WMD -5.42 [95\%CI $-23.55 ; 12.71]$.

Very low quality evidence was provided (serious limitations, inconsistency, and imprecision) for the effectiveness of LLLT + exercise compared to sham LLLT + exercise on pain intensity at short-term follow-up, but not for disability.

\section{Low-Level laser therapy versus exercise}

One study [27] compared the effectiveness of LLLT with exercise therapy post-treatment. No statistically significant difference was found between both therapy groups on pain level and disability.

The effectiveness of patient education

\section{Patient education versus active non-educational interventions}

Three studies $[25,39,51]$, one with a low risk of bias, compared the effectiveness of patient education with physiotherapy [25], Swedish Back School [51] and exercise/yoga exercises [39].

Sherman et al. [39] compared the effectiveness of yoga exercises and conventional exercises with education on the outcome disability. Post-treatment, there was a statistically significant difference between the yoga exercise group and the education group in favour of the yoga group (WMD $-3.4[95 \% \mathrm{CI}-5.1 ;-1.6])$. No statistically significant difference was found between the conventional exercise group and the education group.

Pain and disability at short-term follow-up were reported by Goldby et al. [25] and no significant difference between the education group and the exercise group was found for both outcome measures at this time point.

Two studies [25, 51] reported on pain intensity at intermediate follow-up and the WMD was -9.20 [95\%CI $-23.55 ; 22.45]$.

Disability at intermediate follow-up was reported by three studies [25, 39, 51]; the pooled WMD was 3.16 [95\%CI $-3.97 ; 10.29]$. Long-term follow-up data on pain intensity and disability were reported by two studies $[25$, 51] and the pooled WMDs were -5.54 [95\% CI -15.80 ; 5.12] and -0.96 [95\% CI $-4.80 ; 2.88]$, respectively.

Due to serious limitations, inconsistency, and imprecision, low quality evidence is provided that there is no difference in effect at intermediate and long-term effect on pain and disability for patient education compared to active non-educational interventions.

\section{Patient education: focus on anatomy versus focus on neurosystem}

One study [89] with a high risk of bias compared oneon-one education with a focus on anatomy compared to a focus on the neurosystem in 58 patients who presented themselves at private rehabilitation clinics. Fifteen weekdays after the first session, a significant reduction in disability was found in the group with focus on the neurosystem compared to the control group. However, no differences on pain perception were found.

The effectiveness of massage therapy

Three studies [65-67] with a high risk of bias compared massage therapy with relaxation therapy [65, 67] and acupuncture massage [66]. Post-treatment, there was no statistical significant reduction in pain intensity in the massage group compared to the control group; the pooled WMD was -0.93 [95\%CI -8.51$]$.

Low quality evidence (serious limitations, imprecision) was provided that there was no statistically significant difference in effect of massage therapy compared to passive interventions on pain intensity post-treatment.

\section{The effectiveness of traction}

One study [90] $(n=42)$ with a high risk of bias compared motorized traction treatment plus standard physiotherapy with standard physiotherapy only. No statistically significant differences were found on pain intensity, disability, and recovery at post-treatment and after 3 months followup between both intervention groups. 
The effectiveness of behavioural treatment

As much as 21 randomized trials were identified investigating the effectiveness of behavioural treatment in chronic low back patients.

\section{Behavioural treatment versus no treatment/waiting list controls/placebo}

A total of 12 studies, of which 3 studies [41, 74, 79] had a low risk of bias, were identified comparing some type of behavioural treatment to waiting list controls, no treatment, or a placebo treatment.

Respondent therapy (progressive relaxation) Three studies [82, 83, 85] compared progressive relaxation (respondent therapy) with waiting list controls or placebo. The pooled WMD post-treatment for pain intensity was -19.74 [95\%CI $-34.32 ;-5.16$ ] and -5.24 [95\%CI -8.42 ; $-2.06]$ for disability. No short- or long-term results were reported in these studies.

Respondent therapy (EMG biofeedback) A total of four studies [70, 76, 79, 82] were identified comparing EMG biofeedback (respondent therapy) with waiting list controls or placebo. The WMD for pain intensity of the three studies of which the data could be pooled was -8.67 [95\%CI $-13.59 ;-3.74]$. Disability data were only available of 2 studies and the pooled WMD post-treatment was -7.33 [95\% CI -21.38; 6.73].

Operant therapy Four studies [41, 43, 74, 84], of which three could be pooled, were identified comparing operant therapy with waiting list controls. Post-treatment there was a significant reduction in pain intensity compared to the waiting list controls (WMD -7.00 [95\%CI -12.33; $-1.67])$. The pooled WMD for disability was -2.87 [95\%CI $-7.15 ; 1.41]$. No short- or long-term results were reported in these studies. The study of Kole-Snijders [74], with a low risk of bias, showed a significant decrease in negative affect, motoric behaviour and coping control in the operant behavioural treatment group compared to the waiting list control group at posttreatment.

Combined respondent and cognitive therapy Four studies were identified comparing a combination of respondent and cognitive behavioural treatment with waiting list controls. The WMDs for post-treatment pain intensity and disability were $-12.74[95 \% \mathrm{CI}-24.10 ;-1.37]$ and -2.60 [95\%CI $-6.48 ; 1.27]$, respectively. No short- or long-term results were reported in these studies.
Cognitive therapy Two studies $[69,85]$ were identified comparing the post-treatment effectiveness of cognitive treatment compared with waiting list controls. The pooled WMD for pain intensity was -12.67 [95\%CI -20.26 ; -5.08 ]. Post-treatment disability was only described by Turner et al. in 1993 and a significant decreased pain intensity between the pre- and post-treatment was found for the patients in the cognitive behavioural group, but not for the waiting list control group. One study [69] with a high risk of bias, reported on pain intensity at 3 months followup and found no statistical significant difference between the internet-based cognitive therapy group and the waiting list controls. One study [72] with a high risk of bias reported on the intermediate follow-up effects of cognitive therapy compared to waiting list controls. No statistically significant differences were found for pain intensity and disability between both intervention groups at 6 months follow-up.

Summarized, there is low quality evidence (serious limitations, inconsistency) provided for the effectiveness of behavioural therapy compared to no treatment/waiting list controls/placebo for pain intensity and disability at shortterm follow-up.

\section{Behavioural treatment in addition to an other treatment versus the other treatment alone}

Seven studies compared one type of behavioural treatment plus an additional treatment with the additional treatment alone [41, 43, 68, 77, 78, 81, 87]. Three studies [41, 43, 77], one with a low risk of bias, compared operant therapy plus exercise/physiotherapy with exercise/physiotherapy alone and the WMD for pain intensity and disability posttreatment were $-8.06[95 \% \mathrm{CI}-23.02 ; 6.91]$ and -1.43 [95\%CI -3.68; 0.82], respectively. At intermediate followup the WMD for pain and disability were respectively 0.40 [95\%CI $-5.00 ; 5.80]$ and 1.26 [95\%CI $-1.78 ; 4.29]$. Four other studies $[68,77,78,81]$ compared the effectiveness of cognitive therapy in combination with a standard inpatient program, physiotherapy, and usual GP care with these treatments alone. The post-treatment WMD for pain and disability were -0.03 [95\%CI $-6.72 ; 6.65]$ and -3.88 [95\% CI $-8.65 ; 0.89$ ], respectively.

The pooled WMDs at intermediate follow-up showed no statistically significant differences on pain intensity and disability $(4.49$ [95\% CI $-1.53 ; 10.50]$ and 1.29 [95\% CI $-4.34 ; 6.91]$, respectively).

One study compared a combination of respondent (biofeedback) and physiotherapy with physiotherapy alone [87]. A significant difference in favour of the combination group was found for pain intensity post-treatment, but also after 6 weeks and 6 months. 
We found a total post-treatment WMD for pain intensity and disability of -2.33 [95\%CI $-6.59 ; 1.93]$ and -1.82 [95\%CI -3.88; 0.24], respectively. At 6 months follow-up the total WMDs for pain intensity and disability were -0.72 [95\%CI $-8.13 ; 6.69$ ] and 1.39 [95\%CI $-0.80 ; 3.59]$, respectively.

Three studies [41, 43, 77] reported on the long-term outcomes pain and disability. Three studies compared a combination of operant behavioural treatment with exercise therapy/physiotherapy with exercise/physiotherapy alone. The WMDs for pain intensity and disability were -1.23 [95\% CI - 7.29; 4.83] and 0.87 [95\%CI -2.32; 4.06], respectively. One study also compared a combination of cognitive treatment with physiotherapy with physiotherapy alone. We found a non-significant total WMD for longterm pain intensity and disability of -0.16 [95\%CI -6.03 ; 5.70] and 0.85 [95\% CI $-2.28 ; 3.98]$, respectively.

Smeets et al. [41] compared operant therapy in combination with exercise with exercise therapy alone and was the only study reporting on the outcome recovery. No significant differences were found post-treatment and at 6-months follow-up. However, a statically significant difference in favour of the exercise group was found at 12 months follow-up.

Only two studies $[68,81]$ reported on return to work and sick leave. Altmaier et al. [68] found that $48 \%$ in the behavioural treatment group had returned to work after 6 months, compared to $67 \%$ in the control group. However, this difference was not statically significant. Schweikert et al. [81] reported on the costs due to sick leave. During follow-up, the costs were lower in the cognitive behavioural group than in the usual care group.

Summarized, there is low to moderate quality evidence (serious limitations, inconsistency) provided for not finding an effect of behavioural therapy in addition to another treatment compared to the other treatment alone in pain intensity and disability at short- and long-term follow-up.

\section{Behavioural treatment versus other kinds of treatment}

A total of six studies compared some kind of behavioural treatment with another treatment. Two studies [41, 43] compared operant behavioural treatment with exercise therapy, one study [88] compared operant therapy with physiotherapy, one study [75] compared respondent therapy (muscle relaxation) with self-hypnosis, one study [73] compared cognitive treatment with usual GP care, and one study [71] compared operant therapy and respondent therapy (biofeedback) with education. All studies reported on pain intensity, four studies reported on disability, and two studies reported on global recovery.

Post-treatment pain intensity was reported by four studies and the WMD for operant treatment was -1.61
[95\%CI -6.83; 3.60] and for respondent (biofeedback) therapy $-11.33[95 \% \mathrm{CI}-22.81 ; 0.16 ; \mathrm{Q}=0.23, d f 1]$. The total non-significant WMD for post-treatment pain intensity was $-2.91[95 \% \mathrm{CI}-7.96 ; 2.13]$.

Disability post-treatment was reported by three studies, all comparing operant therapy with exercise therapy/ physiotherapy and the total WMD was -0.32 [95\% CI $-3.32 ; 2.68]$.

Short-term follow-up results were reported by four studies [71, 73, 75, 88]. The WMD for pain intensity for operant therapy was -1.86 [95\%CI $-9.97 ; 6.25]$, for respondent therapy (biofeedback) -5.03 [95\%CI -18.15 ; 8.10] and the total WMD for pain intensity was -5.00 [95\%CI -10.08; 0.07]. Disability was reported by two studies [73, 88], of which one had a low risk of bias, and the total WMD for disability at short-term follow-up was -0.84 [95\% CI $-5.23 ; 3.64]$.

Three studies, comparing an operant therapy with exercise/physiotherapy reported on the intermediate outcomes pain and disability and the WMDs were -0.11 [95\%CI $-7.64 ; 7.42]$ and -0.28 [95\% CI $-4.16 ; 3.60]$, respectively.

Four studies, of which two with a low risk of bias, reported on pain and disability at 12 months follow-up [41, $43,73,88]$. The significant WMD for pain intensity was $-6.05[95 \% \mathrm{CI}-10.70 ;-1.40]$ and the WMD for disability was -2.04 [95\%CI $-5.19 ; 1.10]$.

Global perceived effect was reported by van der Roer et al. [88] and by Smeets et al. [41] and both studies did not find statistically significant differences between operant behavioural treatment and exercise/physiotherapy, at posttreatment and at 3, 6, and 12 months follow-up.

Summarized, there is low to moderate quality evidence (serious limitations, and inconsistency) provided that there is no difference in effect in pain intensity and disability at short- and long-term follow-up for behavioural therapy compared to other kinds of treatment.

\section{Comparison among different types of behavioural treatment}

Cognitive versus operant One study [77] $(n=20)$ with a high risk of bias compared cognitive to operant therapy. All groups in this study also received a physiotherapy backeducation and exercise program. The operant therapy group reported a significantly greater improvement in general function status, but not in pain intensity.

Cognitive versus respondent therapy Two studies ( $n=67)$ with a high risk of bias compared cognitive to respondent therapy consisting of progressive muscle relaxation training $[83,85]$. The pooled WMD $(n=67)$ for post-treatment pain intensity was -3.02 [95\%CI -13.55 ; 7.52] and for disability 2.31 [95\%CI $-1.42 ; 6.04]$. Only 
one study $(n=33)$ reported on long-term pain and disability, and these outcomes were not statistically significantly different between the groups [85].

Due to serious limitations and imprecision, low quality evidence is provided for that there is no effect at posttreatment on pain and disability for cognitive compared to respondent therapy.

Operant therapy versus respondent One study with a high risk of bias compared operant therapy (relaxation training) with respondent biofeedback therapy [71]. No statically significant differences were found on short- and long-term (4 years) follow-up.

Cognitive-behavioural versus cognitive Only one study $(n=33)$ with a high risk of bias included a comparison between groups receiving cognitive-behavioural therapy and cognitive therapy [85]. The cognitive-behavioural therapy consisted of cognitive therapy plus progressive muscle relaxation and imagery. There were neither posttreatment nor long-term statistically significant differences between the groups on any of the outcome measures (global improvement, disability, and pain intensity).

Cognitive-behavioural versus operant therapy Two studies, one with a low risk of bias, were identified [74, 84]. One study compared cognitive-behavioural therapy to operant therapy and found statistically significant better post-treatment results on pain behaviour, and physical functioning with operant therapy, but no differences between the groups after 6 and 12-month follow-up [84]. The second study reported better pain control post-treatment with cognitive-behavioural therapy, but no other posttreatment or long-term differences [74].

Cognitive-behavioural versus respondent therapy One study $(n=28)$ with a high risk of bias was identified [76]. Cognitive-behavioural therapy was compared to EMG biofeedback. No significant differences were found between the groups for pain or any of the outcome measures in the behavioural domain, at either post-treatment or 6-month follow-up.

Operant therapy: in vivo exposure versus graded activity One study $(n=85)$ with a low risk of bias compared an exposure in vivo treatment with a graded activity program [86]. No significant differences on pain intensity and disability at post-treatment or 6-month follow-up were identified between both intervention groups.

Cognitive-behavioural treatment: group or individual therapy One study compared the effectiveness of cognitive-behavioural group treatment with individual treatment
[80]. No significant effects of group membership (individual vs. group) on pain intensity and disability were demonstrated post-treatment and at 6 months follow-up.

The effectiveness of multidisciplinary treatment

\section{Multidisciplinary treatment versus no treatment/waiting list controls}

Three studies were identified comparing a multidisciplinary treatment with no treatment or waiting list controls [92, 93, 96]. Jackel et al. [93] reported on post-treatment pain intensity and found a statistical significant difference in favour of the multidisciplinary treatment compared to the waiting list controls.

Two studies [92, 96] reported on short-term pain intensity and the significant pooled WMD was -9.47 [95\% CI $-13.87 ;-5.07 ; \mathrm{Q}=0.11, d f 1]$ and the pooled WMD for disability was -8.84 [95\%CI -18.49 ; 0.82 ; $\mathrm{Q}=2.51, d f 1]$. Long-term outcomes revealed no statistically significant differences between a multidisciplinary rehabilitation and no treatment. The long-term non-significant WMDs for pain intensity and disability were -9.27 [95\%CI -27.86; 9.12; $\mathrm{Q}=6.71, d f 1]$ and -0.77 [95\%CI $-4.62 ; 3.08 ; \mathrm{Q}=0.46, d f 1]$, respectively. Therefore, there is moderate quality evidence for the effectiveness of multidisciplinary treatment on short-term pain intensity compared to no treatment/waiting list controls and there is moderate quality evidence for not finding an effect on disability and on long-term outcomes.

One study [92] reported on sick leave and found a statistically significant difference at 4-months follow-up between the treated and the non-treated group; the median days of sick leave in the intervention group was 10 days compared to 122 days in the control group.

\section{Multidisciplinary treatment versus other kinds of active treatment}

Four studies [15, 91, 94, 95] were identified comparing a multidisciplinary treatment with inpatient exercises [91], physiotherapy [94], usual care [95], and exercise therapy [15].

One study reported on post-treatment disability and found no significant difference between both intervention groups [95].

Short-term pain intensity was reported in two studies $[15,91]$ and the statistically significant pooled WMD was -11.55 [95\% CI $-19.68 ;-3.43$ ]. One study [15] reported on functional outcome and found a significant difference between both groups in favour of the multidisciplinary treatment at short-term follow-up. 
Only one study [94] with a low risk of bias reported on intermediate pain intensity and disability and no statistically significant differences between the two groups were found.

Two studies [91, 94] reported on long-term pain intensity and we found a non-significant pooled WMD of -3.34 [95\%CI $-11.64 ; 4.97]$. Only one study [94], with a low risk of bias, reported on long-term (12 and 24 months) disability and found no statistically significant difference between multidisciplinary treatment and physiotherapy.

One study [15] with a low risk of bias, reported on workreadiness and found a highly significant difference between the multidisciplinary intervention and the exercise intervention; $75 \%$ of the patients in the multidisciplinary group achieved work-readiness at 4 months compared to $42 \%$ in the active treatment group. Another study with a low risk of bias reported on sick leave and found no significant difference between both intervention groups, 1 and 2 years after rehabilitation [94].

One study [15] with a low risk of bias reported on pain, disability, and return to work after 5 years follow-up. No significant differences were found on pain intensity; however, patients in the multidisciplinary treatment group showed a lower disability level compared to the patients in the exercise group.

Summarized, there is moderate evidence for the effectiveness of multidisciplinary treatment compared to other kinds of active treatment on pain intensity at short-term follow-up and there is also moderate evidence that there is no statistically significant difference on pain intensity at long-term follow-up.

\section{Outpatient versus inpatient multidisciplinary treatment}

One study [96] ( $n=316$ ) with a high risk of bias compared a 3-week inpatient back school rehabilitation program with a 15-session outpatient back school rehabilitation program. No statistically significant differences were found between both intervention groups at short-term as well as on the long-term follow-up.

\section{Discussion}

In this review, $83 \mathrm{RCTs}$ were included that evaluated the effectiveness of physical and rehabilitation interventions for non-specific chronic LBP.

The effectiveness of physical and rehabilitation treatment strategies

No significant treatment effects of exercise therapy compared to no treatment/waiting list controls were found on pain intensity and disability. Although, compared to usual care, pain intensity and disability were significantly reduced by exercise therapy at short-term follow-up.

We found no difference in effectiveness of TENS and sham TENS and there were also no differences between TENS and active treatments. All types of behavioural therapy were more effective in reducing pain intensity than waiting list controls, but it is unknown whether this also applies to back-specific function. Additionally, there are some indications that the addition of behavioural components can reduce sick leave and costs due to sick leave. However, further research is encouraged to confirm these findings. Finally, multidisciplinary treatment was found to be more effective in reducing pain intensity compared to no treatment/waiting list controls and active treatments (e.g. exercise therapy, physiotherapy, and usual care), and sick leave is reduced at short-term follow-up.

Adverse events were not reported in any of the included studies.

None of the significant differences found in this overview study reached a difference larger than $10 \%$, where in most studies a difference of $15-20 \%$ is defined as clinically relevant. Therefore, the differences found in this overview must be regarded as small and not clinically relevant.

Of particular note is the heterogeneity in some of the analyses among the studies. This heterogeneity could have been caused by differences in interventions, differences in control groups, duration of the intervention, and the risk of bias of the different studies. Therefore, the results of the meta-analyses with heterogeneity should be interpreted with some caution.

This review showed that behavioural therapy has an effect on pain intensity. This is apparent because the aim of behavioural therapy is not to treat pain, but to modify one of the three response systems (behavioural, cognition, and physiological reactivity [107]). The decrease in pain intensity might be related to the combination of different treatment strategies applied in a great number of the included studies.

It was apparent that there were no studies identified studying the effectiveness of lumbar support for the treatment of chronic LBP and few studies were found for massage therapy and traction. Therefore, further research is encouraged to identify the effectiveness of these interventions.

Two of the earlier conducted reviews on the described interventions were conducted on chronic low back patients only: behavioural therapy and TENS [4, 9]. Because we applied strict criteria for "chronic low back pain", not all studies included in that reviews were included in our overview. When we compare the results of the study from Ostelo et al. on behavioural treatment to ours, it is apparent that Ostelo et al. found strong evidence in favour of a combined respondent-cognitive therapy for medium 
positive effect on pain while we conclude to have low quality evidence for the effectiveness of behavioural therapy compared to no treatment/waiting list controls/placebo for pain intensity and disability at short term [9]. This difference is probably caused by the different inclusion criteria used on chronic LBP and the different methods used to define the level of evidence. If we compare the conclusion of the Cochrane review from Khadilkar et al. on the effectiveness of TENS versus placebo with our overview, we can conclude that the conclusions drawn are very comparable; both conclude that TENS is not supported compared to placebo in the management of chronic LBP [4].

\section{Methodological considerations}

The methodological quality of the studies was generally poor. Many methodological criteria regarding the internal validity of the studies were not fulfilled. Only two studies fulfilled all 11 items [33, 63]. Blinding of the patient and blinding of the care provider were not properly conducted in many studies. Blinding of patients is also difficult in many RCTs investigating the effectives of exercise therapy, back schools, education, behavioural treatment, and multidisciplinary rehabilitation. The quality of future RCTs in the field of back pain should be improved to reduce bias in systematic reviews and overviews, as it has been demonstrated that statistical pooling of low quality trials results in overestimation of treatment effects.

Overall, evidence provided from the meta-analyses in this overview study was low. In the most analyses there were serious limitations regarding the methodological quality and in most analyses there was imprecision of data because of sparse data and wide confidence intervals. Additionally, in some analysis there was a matter of inconsistency because of heterogeneity. Therefore, further research is very likely to have an important impact on our confidence in the estimate of effect and is likely to change the estimate.

\section{Strengths and limitations}

Several biases can be introduced by literature search and selection procedure. We might have missed relevant unpublished trials, which are more likely to be small studies with non-significant results, leading to publication bias. Screening references of identified trials and systematic reviews may result in an over representation of positive studies in the review, because trials with a positive result are more likely to be referred to in other publications, leasing to reference bias. Studies not published in English, Dutch, or German were not included in this review. It is not clear whether a language restriction is associated with bias [108].
Subgroups were pooled because of the clinical homogeneity. However, methodological heterogeneity occurred in some of the comparisons between different interventions strategies.

Only a small number of the studies were rated as high quality and this may have led to an overestimation of effect. Also, studies may lack information to assess quality and clinical relevance. The only outcome measure used in the majority of studies was pain intensity, limiting the ability to report on other important outcomes. Because of the relatively small number of studies pooled within the different subgroups, it was not possible to conduct a sensitivity analysis. However, with the GRADE method applied, we have tried to account for the risk of bias found in the different studies.

\section{Implications for practice}

The most promising interventions for a physical and rehabilitation treatment in chronic LBP patients are a multidisciplinary treatment or behavioural treatment. All types of behavioural therapy were more effective in reducing pain intensity than waiting list controls. Multidisciplinary treatment was found to be more effective in reducing pain intensity compared to no treatment/waiting list controls and active treatments (e.g. exercise therapy, physiotherapy, and usual care), and sick leave is reduced at short-term follow-up. Additionally, there are some indications that the addition of behavioural components can reduce sick leave and costs due to sick leave. Also exercise therapy reduced pain intensity and disability significantly compared to usual care.

Finally, there appeared to be insufficient data to draw firm conclusion on the clinical effect of back schools, lowlevel laser therapy, patient education, massage, traction, superficial heat/cold, and lumbar supports.

Because of the lack of evidence and the conflicting evidence on the effectiveness of different interventions discussed in this review, only multidisciplinary treatment, behavioural treatment, and exercise therapy should be provided as conservative treatments in daily practice in the treatment of chronic LBP.

Implications for research

To conclude, we identified 83 RCTs that evaluated treatment effects for patients with chronic non-specific LBP. Most of the studies included in this review showed methodological deficiencies.

For future research the focus should be on high-quality RCTs with sufficient sample size to be able to draw firm conclusions. Interventions under study should be the ones which seem to be promising, but where evidence is still 
unclear or insufficient, such as multidisciplinary treatments, education, and exercise. For example, a large highquality study comparing exercise therapy and education with a wait and see approach could give the evidence for the effectiveness of exercise therapy compared to education or a wait and see approach, and of education compared to a wait and see approach. Additionally, comparing the multidisciplinary approach to exercise therapy alone could give insight in the additional value of the multidisciplinary approach, which is probably more expensive than a single exercise program. This also implies that cost-effectiveness studies are needed to make a cost-benefit consideration.

Finally focus in research on specific subgroups of LBP patients for whom a certain intervention is most effective is also needed. Some patients might respond better to exercise therapy than others, but insight in the patient characteristics of such a subgroup is still lacking.

Acknowledgments Funding was provided by the Dutch National Health Insurance Council.

\section{Conflict of interest statement None.}

Open Access This article is distributed under the terms of the Creative Commons Attribution Noncommercial License which permits any noncommercial use, distribution, and reproduction in any medium, provided the original author(s) and source are credited.

\section{References}

1. Andersson GB (1999) Epidemiological features of chronic lowback pain. Lancet 354:581-585

2. Abenhaim L, Rossignol M, Valat JP, Nordin M, Avouac B, Blotman F, Charlot J, Dreiser RL, Legrand E, Rozenberg S, Vautravers P (2000) The role of activity in the therapeutic management of back pain. Report of the International Paris Task Force on Back Pain. Spine 25:1S-33S

3. Heymans MW, van Tulder MW, Esmail R, Bombardier C, Koes BW (2004) Back schools for non-specific low-back pain. Cochrane Database Syst Rev:CD000261

4. Khadilkar A, Milne S, Brosseau L, Robinson V, Saginur M, Shea B, Tugwell P, Wells G (2005) Transcutaneous electrical nerve stimulation (TENS) for chronic low-back pain. Cochrane Database Syst Rev:CD003008

5. French SD, Cameron M, Walker BF, Reggars JW, Esterman AJ (2006) A Cochrane review of superficial heat or cold for low back pain. Spine 31:998-1006

6. Baxter GD, Bell AJ, Allen JM, Ravey J (1991) Low-level laser therapy: current clinical practice in Northern Ireland. Physiotherapy 77:171-178

7. Engers A, Jellema P, Wensing M, van der Windt DA, Grol R, van Tulder MW (2008) Individual patient education for low back pain. Cochrane Database Syst Rev:CD004057

8. Furlan AD, Brosseau L, Imamura M, Irvin E (2002) Massage for low-back pain: a systematic review within the framework of the Cochrane Collaboration Back Review Group. Spine 27:1896-1910
9. Ostelo RW, van Tulder MW, Vlaeyen JW, Linton SJ, Morley SJ, Assendelft WJ (2005) Behavioural treatment for chronic low-back pain. Cochrane Database Syst Rev:CD002014

10. van Duijvenbode IC, Jellema P, van Poppel MN, van Tulder MW (2008) Lumbar supports for prevention and treatment of low back pain. Cochrane Database Syst Rev:CD001823

11. Clarke JA, van Tulder MW, Blomberg SE, de Vet HC, van der Heijden GJ, Bronfort G, Bouter LM (2007) Traction for lowback pain with or without sciatica. Cochrane Database Syst Rev:CD003010

12. Guzman J, Esmail R, Karjalainen K, Malmivaara A, Irvin E, Bombardier C (2001) Multidisciplinary rehabilitation for chronic low back pain: systematic review. BMJ 322:1511-1516

13. Atkins D, Best D, Briss PA, Eccles M, Falck-Ytter Y, Flottorp S, Guyatt GH, Harbour RT, Haugh MC, Henry D, Hill S, Jaeschke R, Leng G, Liberati A, Magrini N, Mason J, Middleton P, Mrukowicz J, O'Connell D, Oxman AD, Phillips B, Schunemann HJ, Edejer TT, Varonen H, Vist GE, Williams JW Jr, Zaza S, Group GW (2004) Grading quality of evidence and strength of recommendations. BMJ 328:1490

14. Alexandre NM, de Moraes MA, Correa Filho HR, Jorge SA (2001) Evaluation of a program to reduce back pain in nursing personnel. Rev Saude Publica 35:356-361

15. Bendix AF, Bendix T, Ostenfeld S, Bush E, Andersen A (1995) Active treatment programs for patients with chronic low back pain: a prospective, randomized, observer-blinded study. Eur Spine J 4:148-152

16. Chatzitheodorou D, Kabitsis C, Malliou P, Mougios V (2007) A pilot study of the effects of high-intensity aerobic exercise versus passive interventions on pain, disability, psychological strain, and serum cortisol concentrations in people with chronic low back pain. Phys Ther 87:304-312

17. Critchley DJ, Ratcliffe J, Noonan S, Jones RH, Hurley MV (2007) Effectiveness and cost-effectiveness of three types of physiotherapy used to reduce chronic low back pain disability: a pragmatic randomized trial with economic evaluation. Spine 32:1474-1481

18. Deyo RA, Walsh NE, Martin DC, Schoenfeld LS, Ramamurthy S (1990) A controlled trial of transcutaneous electrical nerve stimulation (TENS) and exercise for chronic low back pain. N Engl J Med 322:1627-1634

19. Donzelli S, Di Domenica E, Cova AM, Galletti R, Giunta N (2006) Two different techniques in the rehabilitation treatment of low back pain: a randomized controlled trial. Eura Medicophys 42:205-210

20. Elnaggar IM, Nordin M, Sheikhzadeh A, Parnianpour M, Kahanovitz N (1991) Effects of spinal flexion and extension exercises on low-back pain and spinal mobility in chronic mechanical low-back pain patients. Spine 16:967-972

21. Ferreira ML, Ferreira PH, Latimer J, Herbert RD, Hodges PW, Jennings MD, Maher CG, Refshauge KM (2007) Comparison of general exercise, motor control exercise and spinal manipulative therapy for chronic low back pain: a randomized trial. Pain 131:31-37

22. Frost H, Lamb SE, Doll HA, Carver PT, Stewart-Brown S (2004) Randomised controlled trial of physiotherapy compared with advice for low back pain. Bmj 329:708

23. Galantino ML, Bzdewka TM, Eissler-Russo JL, Holbrook ML, Mogck EP, Geigle P, Farrar JT (2004) The impact of modified Hatha yoga on chronic low back pain: a pilot study. Altern Ther Health Med 10:56-59

24. Gladwell V, Head S, Haggar M, Beneke R (2006) Does a program of Pilates improve chronic non-specific low back pain? J Sport Rehabil 15:338-350 
25. Goldby LJ, Moore AP, Doust J, Trew ME (2006) A randomized controlled trial investigating the efficiency of musculoskeletal physiotherapy on chronic low back disorder. Spine 31:1083-1093

26. Gudavalli MR, Cambron JA, McGregor M, Jedlicka J, Keenum M, Ghanayem AJ, Patwardhan AG (2006) A randomized clinical trial and subgroup analysis to compare flexion-distraction with active exercise for chronic low back pain. Eur Spine J 15:1070-1082

27. Gur A, Karakoc M, Cevik R, Nas K, Sarac AJ, Karakoc M (2003) Efficacy of low power laser therapy and exercise on pain and functions in chronic low back pain. Lasers Surg Med $32: 233-238$

28. Hildebrandt VH, Proper KI, van den Berg R, Douwes M, van den Heuvel SG, van Buuren S (2000) [Cesar therapy is temporarily more effective in patients with chronic low back pain than the standard treatment by family practitioner: randomized, controlled and blinded clinical trial with 1 year follow-up] Cesar-therapie tijdelijk effectiever dan standaardbehandeling door de huisarts bij patienten met chronische aspecifieke large rugklachten; gerandomiseerd, gecontroleerd en geblindeerd onderzoek met 1 jaar follow-up. Ned Tijdschr Geneeskd 144:2258-2264

29. Johannsen F, Remvig L, Kryger P, Beck P, Warming S, Lybeck K, Dreyer V, Larsen LH (1995) Exercises for chronic low back pain: a clinical trial. J Orthop Sports Phys Ther 22:52-59

30. Kankaanpaa M, Taimela S, Airaksinen O, Hanninen O (1999) The efficacy of active rehabilitation in chronic low back pain. Effect on pain intensity, self-experienced disability, and lumbar fatigability. Spine 24:1034-1042

31. Lewis JS, Hewitt JS, Billington L, Cole S, Byng J, Karayiannis $S$ (2005) A randomized clinical trial comparing two physiotherapy interventions for chronic low back pain. Spine 30:711-721

32. Machado LA, Azevedo DC, Capanema MB, Neto TN, Cerceau DM (2007) Client-centered therapy vs exercise therapy for chronic low back pain: a pilot randomized controlled trial in Brazil. Pain Med 8:251-258

33. Mannion AF, Muntener M, Taimela S, Dvorak J (1999) A randomized clinical trial of three active therapies for chronic low back pain. Spine 24:2435-2448

34. Marshall P, Murphy B (2008) Self-report measures best explain changes in disability compared with physical measures after exercise rehabilitation for chronic low back pain. Spine 33:326-338

35. Niemisto L, Lahtinen-Suopanki T, Rissanen P, Lindgren KA, Sarna S, Hurri H (2003) A randomized trial of combined manipulation, stabilizing exercises, and physician consultation compared to physician consultation alone for chronic low back pain. Spine 28:2185-2191

36. Risch SV, Norvell NK, Pollock ML, Risch ED, Langer H, Fulton M, Graves JE, Leggett SH (1993) Lumbar strengthening in chronic low back pain patients. Physiologic and psychological benefits. Spine 18:232-238

37. Rittweger J, Just K, Kautzsch K, Reeg P, Felsenberg D (2002) Treatment of chronic lower back pain with lumbar extension and whole-body vibration exercise: a randomized controlled trial. Spine 27:1829-1834

38. Roche G, Ponthieux A, Parot-Shinkel E, Jousset N, Bontoux L, Dubus V, Penneau-Fontbonne D, Roquelaure Y, Legrand E, Colin D, Richard I, Fanello S (2007) Comparison of a functional restoration program with active individual physical therapy for patients with chronic low back pain: a randomized controlled trial. Arch Phys Med Rehabil 88:1229-1235

39. Sherman KJ, Cherkin DC, Erro J, Miglioretti DL, Deyo RA (2005) Comparing yoga, exercise, and a self-care book for chronic low back pain: a randomized, controlled trial. Ann Intern Med 143:849-856
40. Sjögren T, Nissinen KJ, Jarvenpaa SK, Ojanen MT, Vanharanta H, Malkia EA (2005) Effects of a workplace physical exercise intervention on the intensity of headache and neck and shoulder symptoms and upper extremity muscular strength of office workers: a cluster randomized controlled cross-over trial. Pain 116:119-128

41. Smeets RJ, Vlaeyen JW, Hidding A, Kester AD, van der Heijden GJ, van Geel AC, Knottnerus JA (2006) Active rehabilitation for chronic low back pain: cognitive-behavioral, physical, or both? First direct post-treatment results from a randomized controlled trial [ISRCTN22714229]. BMC Musculoskelet Disord 7:5

42. Tritilanunt T, Wajanavisit W (2001) The efficacy of an aerobic exercise and health education program for treatment of chronic low back pain. J Med Assoc Thai 84(Suppl 2):S528-S533

43. Turner JA, Clancy S, McQuade KJ, Cardenas DD (1990) Effectiveness of behavioral therapy for chronic low back pain: a component analysis. J Consult Clin Psychol 58:573-579

44. Williams KA, Petronis J, Smith D, Goodrich D, Wu J, Ravi N, Doyle EJ Jr, Gregory Juckett R, Munoz Kolar M, Gross R, Steinberg L (2005) Effect of Iyengar yoga therapy for chronic low back pain. Pain 115:107-117

45. Yelland MJ, Glasziou PP, Bogduk N, Schluter PJ, McKernon M (2004) Prolotherapy injections, saline injections, and exercises for chronic low-back pain: a randomized trial. Spine 29:9-16 (discussion 16)

46. Yozbatiran N, Yildirim Y, Parlak B (2004) Effects of fitness and aquafitness exercises on physical fitness in patients with chronic low back pain. Pain Clinic 16:35-42

47. Chown M, Whittamore L, Rush M, Allan S, Stott D, Archer M (2008) A prospective study of patients with chronic back pain randomised to group exercise, physiotherapy or osteopathy. Physiotherapy 94:21-28

48. Harts CC, Helmhout PH, de Bie RA, Staal JB (2008) A highintensity lumbar extensor strengthening program is little better than a low-intensity program or a waiting list control group for chronic low back pain: a randomised clinical trial. Aust J Physiother 54:23-31

49. Koldas Dogan S, Sonel Tur B, Kurtais Y, Atay MB (2008) Comparison of three different approaches in the treatment of chronic low back pain. Clin Rheumatol 27:873-881

50. Tekur P, Singphow C, Nagendra HR, Raghuram N (2008) Effect of short-term intensive yoga program on pain, functional disability, and spinal flexibility in chronic low back pain: a randomized control study. J Altern Complement Med 14:637-644

51. Hurri H (1989) The Swedish back school in chronic low back pain. Part I. Benefits. Scand J Rehabil Med 21:33-40

52. Keijsers JF, Groenman NH, Gerards FM, van Oudheusden E, Steenbakkers M (1989) A back school in The Netherlands: evaluating the results. Patient Educ Couns 14:31-44

53. Klaber Moffet J, Chase S, Portek I, Ennis J (1986) A controlled prospective study to evaluate the effectiveness of a back school in the relief of chronic low-back pain. Spine 11:120-122

54. Tavafian SS, Jamshidi A, Mohammad K, Montazeri A (2007) Low back pain education and short term quality of life: a randomized trial. BMC Musculoskelet Disord 8:21

55. Ribeiro LH, Jennings F, Jones A, Furtado R, Natour J (2008) Effectiveness of a back school program in low back pain. Clin Exp Rheumatol 26:81-88

56. Ghoname EA, Craig WF, White PF, Ahmed HE, Hamza MA, Henderson BN, Gajraj NM, Huber PJ, Gatchel RJ (1999) Percutaneous electrical nerve stimulation for low back pain: a randomized crossover study. JAMA 281:818-823

57. Grant DJ, Bishop-Miller J, Winchester DM, Anderson M, Faulkner S (1999) A randomized comparative trial of acupuncture versus transcutaneous electrical nerve stimulation for chronic back pain in the elderly. Pain 82:9-13 
58. Jarzem PF, Harvey EJ, Arcaro N, Kaczorowski J (2005) Transcutaneous Electrical Nerve Stimulation [TENS] for Chronic Low Back Pain. J Musculoskelet Pain 13:3-9

59. Jarzem PF, Harvey EJ, Arcaro N, Kaczorowski J (2005) Transcutaneous electrical nerve stimulation [TENS] for shortterm treatment of low back pain-randomized double blind crossover study of sham verus conventional TENS. J Musculoskelet Pain 13:11-17

60. Yokoyama M, Sun X, Oku S, Taga N, Sato K, Mizobuchi S, Takahashi T, Morita K (2004) Comparison of percutaneous electrical nerve stimulation with transcutaneous electrical nerve stimulation for long-term pain relief in patients with chronic low back pain. Anesth Analg 98:1552-1556 (table of contents)

61. Topuz O, Özfidan E, Ozgen M, Ardic F (2004) Efficacy of transcutaneous electrical nerve stimulation and percutaneous neuromodulation therapy in chronic low back pain. J Back Musculoskelet Rehabil 17:127-133

62. Djavid GE, Mehrdad R, Ghasemi M, Hasan-Zadeh H, SotoodehManesh A, Pouryaghoub G (2007) In chronic low back pain, low level laser therapy combined with exercise is more beneficial than exercise alone in the long term: a randomised trial. Aust $\mathrm{J}$ Physiother 53:155-160

63. Klein RG, Eek BC (1990) Low-energy laser treatment and exercise for chronic low back pain: double-blind controlled trial. Arch Phys Med Rehabil 71:34-37

64. Soriano S, Rios R (1998) Gallium arsenide laser treatment of chronic low back pain: a prospective, randomized and double blind study. Laser Ther 10:175-180

65. Field T, Hernandez-Reif M, Diego M, Fraser M (2007) Lower back pain and sleep disturbance are reduced following massage therapy. J Bodywork Mov Ther 11:141-145

66. Franke A, Gebauer S, Franke K, Brockow T (2000) Akupunktmassage nach Penzel versus klassische Teilmassage und Einzel- versus Gruppenkrankengymnastik bei chronischen Rückenschmerzen - eine randomisierte, kontrollierte klinische Studie in 2x2-faktoriellem Design. Forsch Komplementärmed Klass Naturheilkunde 7:286-293

67. Hernandez-Reif M, Field T, Krasnegor J, Theakston H (2001) Lower back pain is reduced and range of motion increased after massage therapy. Int J Neurosci 106:131-145

68. Altmaier EM, Lehmann TR, Russell DW, Weinstein JN, Kao CF (1992) The effectiveness of psychological interventions for the rehabilitation of low back pain: a randomized controlled trial evaluation. Pain 49:329-335

69. Buhrman M, Faltenhag S, Strom L, Andersson G (2004) Controlled trial of Internet-based treatment with telephone support for chronic back pain. Pain 111:368-377

70. Bush C, Ditto B, Feuerstein M (1985) A controlled evaluation of paraspinal EMG biofeedback in the treatment of chronic low back pain. Health Psychol 4:307-321

71. Donaldson S, Romney D, Donaldson M, Skubick D (1994) Randomized study of the application of single motor unit biofeedback training to chronic low back pain. J Occup Rahabil 4:23-37

72. Haas M, Groupp E, Muench J, Kraemer D, Brummel-Smith K, Sharma R, Ganger B, Attwood M, Fairweather A (2005) Chronic disease self-management program for low back pain in the elderly. J Manip Physiol Ther 28:228-237

73. Johnson RE, Jones GT, Wiles NJ, Chaddock C, Potter RG, Roberts C, Symmons DP, Watson PJ, Torgerson DJ, Macfarlane GJ (2007) Active exercise, education, and cognitive behavioral therapy for persistent disabling low back pain: a randomized controlled trial. Spine 32:1578-1585

74. Kole-Snijders AM, Vlaeyen JW, Goossens ME, Rutten-van Molken MP, Heuts PH, van Breukelen G, van Eek H (1999) Chronic low-back pain: what does cognitive coping skills training add to operant behavioral treatment? Results of a randomized clinical trial. J Consult Clin Psychol 67:931-944

75. McCauley JD, Thelen MH, Frank RG, Willard RR, Callen KE (1983) Hypnosis compared to relaxation in the outpatient management of chronic low back pain. Arch Phys Med Rehabil 64:548-552

76. Newton-John TR, Spence SH, Schotte D (1995) Cognitivebehavioural therapy versus EMG biofeedback in the treatment of chronic low back pain. Behav Res Ther 33:691-697

77. Nicholas MK, Wilson PH, Goyen J (1991) Operant-behavioural and cognitive-behavioural treatment for chronic low back pain. Behav Res Ther 29:225-238

78. Nicholas MK, Wilson PH, Goyen J (1992) Comparison of cognitive-behavioral group treatment and an alternative nonpsychological treatment for chronic low back pain. Pain 48:339-347

79. Nouwen A (1983) EMG biofeedback used to reduce standing levels of paraspinal muscle tension in chronic low back pain. Pain 17:353-360

80. Rose MJ, Reilly JP, Pennie B, Bowen-Jones K, Stanley IM, Slade PD (1997) Chronic low back pain rehabilitation programs: a study of the optimum duration of treatment and a comparison of group and individual therapy. Spine 22:2246-2251 (discussion 2252-2253)

81. Schweikert B, Jacobi E, Seitz R, Cziske R, Ehlert A, Knab J, Leidl R (2006) Effectiveness and cost-effectiveness of adding a cognitive behavioral treatment to the rehabilitation of chronic low back pain. J Rheumatol 33:2519-2526

82. Stuckey SJ, Jacobs A, Goldfarb J (1986) EMG biofeedback training, relaxation training, and placebo for the relief of chronic back pain. Percept Mot Skills 63:1023-1036

83. Turner JA (1982) Comparison of group progressive-relaxation training and cognitive-behavioral group therapy for chronic low back pain. J Consult Clin Psychol 50:757-765

84. Turner JA, Clancy S (1988) Comparison of operant behavioral and cognitive-behavioral group treatment for chronic low back pain. J Consult Clin Psychol 56:261-266

85. Turner JA, Jensen MP (1993) Efficacy of cognitive therapy for chronic low back pain. Pain 52:169-177

86. Leeuw M, Goossens ME, van Breukelen GJ, de Jong JR, Heuts PH, Smeets RJ, Koke AJ, Vlaeyen JW (2008) Exposure in vivo versus operant graded activity in chronic low back pain patients: results of a randomized controlled trial. Pain 138:192-207

87. Magnusson ML, Chow DH, Diamandopoulos Z, Pope MH (2008) Motor control learning in chronic low back pain. Spine 33:E532-E538

88. van der Roer N, van Tulder M, Barendse J, Knol D, van Mechelen $\mathrm{W}$, de Vet $\mathrm{H}$ (2008) Intensive group training protocol versus guideline physiotherapy for patients with chronic low back pain: a randomised controlled trial. Eur Spine J 17:1193-1200

89. Moseley GL, Nicholas MK, Hodges PW (2004) A randomized controlled trial of intensive neurophysiology education in chronic low back pain. Clin J Pain 20:324-330

90. Borman P, Keskin D, Bodur H (2003) The efficacy of lumbar traction in the management of patients with low back pain. Rheumatol Int 23:82-86

91. Alaranta H, Rytokoski U, Rissanen A, Talo S, Ronnemaa T, Puukka P, Karppi SL, Videman T, Kallio V, Slatis P (1994) Intensive physical and psychosocial training program for patients with chronic low back pain. A controlled clinical trial. Spine 19:1339-1349

92. Bendix AF, Bendix T, Vaegter K, Lund C, Frolund L, Holm L (1996) Multidisciplinary intensive treatment for chronic low back pain: a randomized, prospective study. Cleve Clin J Med 63:62-69 
93. Jäckel WH, Cziske R, Gerdes N, Jacobi E (1990) Überprüfung der Wirksamkeit stationärer Rehabilitationsmaßnahmen bei Patienten mit chronischen Kreuzschmerzen: eine prospektive, randomisierte, krontrollierte Studie. Rehabilitation 29:129-133

94. Kaapa EH, Frantsi K, Sarna S, Malmivaara A (2006) Multidisciplinary group rehabilitation versus individual physiotherapy for chronic nonspecific low back pain: a randomized trial. Spine 31:371-376

95. Vollenbroek-Hutten MM, Hermens HJ, Wever D, Gorter M, Rinket J, Ijzerman MJ (2004) Differences in outcome of a multidisciplinary treatment between subgroups of chronic low back pain patients defined using two multiaxial assessment instruments: the multidimensional pain inventory and lumbar dynamometry. Clin Rehabil 18:566-579

96. Harkapaa K, Jarvikoski A, Mellin G, Hurri H (1989) A controlled study on the outcome of inpatient and outpatient treatment of low back pain. Part I. Pain, disability, compliance, and reported treatment benefits three months after treatment. Scand $\mathbf{J}$ Rehabil Med 21:81-89

97. Bendix AE, Bendix T, Haestrup C, Busch E (1998) A prospective, randomized 5-year follow-up study of functional restoration in chronic low back pain patients. Eur Spine J 7:111-119

98. Cambron JA, Gudavalli MR, Hedeker D, McGregor M, Jedlicka J, Keenum M, Ghanayem AJ, Patwardhan AG, Furner SE (2006) One-year follow-up of a randomized clinical trial comparing flexion distraction with an exercise program for chronic lowback pain. J Altern Complement Med 12:659-668

99. Cambron JA, Gudavalli MR, McGregor M, Jedlicka J, Keenum M, Ghanayem AJ, Patwardhan AG, Furner SE (2006) Amount of health care and self-care following a randomized clinical trial comparing flexion-distraction with exercise program for chronic low back pain. Chiropr Osteopat 14:19

100. Harkapaa K, Mellin G, Jarvikoski A, Hurri H (1990) A controlled study on the outcome of inpatient and outpatient treatment of low back pain. Part III. Long-term follow-up of pain, disability, and compliance. Scand J Rehabil Med 22:181-188
101. Mellin G, Harkapaa K, Hurri H, Jarvikoski A (1990) A controlled study on the outcome of inpatient and outpatient treatment of low back pain. Part IV. Long-term effects on physical measurements. Scand J Rehabil Med 22:189-194

102. Mellin G, Hurri H, Harkapaa K, Jarvikoski A (1989) A controlled study on the outcome of inpatient and outpatient treatment of low back pain. Part II. Effects on physical measurements three months after treatment. Scand J Rehabil Med 21:91-95

103. Niemisto L, Rissanen P, Sarna S, Lahtinen-Suopanki T, Lindgren KA, Hurri H (2005) Cost-effectiveness of combined manipulation, stabilizing exercises, and physician consultation compared to physician consultation alone for chronic low back pain: a prospective randomized trial with 2-year follow-up. Spine 30:1109-1115

104. Smeets RJ, Vlaeyen JW, Hidding A, Kester AD, van der Heijden GJ, Knottnerus JA (2008) Chronic low back pain: physical training, graded activity with problem solving training, or both? The one-year post-treatment results of a randomized controlled trial. Pain 134:263-276

105. Tavafian SS, Jamshidi AR, Montazeri A (2008) A randomized study of back school in women with chronic low back pain: quality of life at three, six, and twelve months follow-up. Spine 33:1617-1621

106. Frost H, Klaber Moffet JA, Moser JS, Fairbank JC (1995) Randomised controlled trial for evaluation of fitness programme for patients with chronic low back pain. BMJ 310:151-154

107. Vlaeyen JW, Haazen IW, Schuerman JA, Kole-Snijders AM, van Eek H (1995) Behavioural rehabilitation of chronic low back pain: comparison of an operant treatment, an operantcognitive treatment and an operant-respondent treatment. $\mathrm{Br} \mathbf{J}$ Clin Psychol 34(Pt 1):95-118

108. Egger M, Smith GD (1998) Bias in location and selection of studies. BMJ 316:61-66 